\title{
Evaluation of the Treatment of High Intensity Focused Ultrasound Combined With Suction Curettage for Exogenous Cesarean Scar Pregnancy
}

\section{Lin Mu (D2308019@zju.edu.cn )}

Zhejiang University, school of medicine, second affiliated hospital https://orcid.org/0000-0002-14492646

\section{Huifang Weng}

The Second Affiliated Hospital, School of Medicine, Zhejiang University

\section{Xiaoyun Wang}

Zhejiang University, school of medicine, second affiliated hospital

\section{Research Article}

Keywords: Exogenous cesarean scar pregnancy, High intensity focused ultrasound, Suction curettage, High-risk factors

Posted Date: December 8th, 2021

DOI: https://doi.org/10.21203/rs.3.rs-740249/v1

License: (c) (i) This work is licensed under a Creative Commons Attribution 4.0 International License. Read Full License

Version of Record: A version of this preprint was published at Archives of Gynecology and Obstetrics on March 18th, 2022. See the published version at https://doi.org/10.1007/s00404-022-06487-3. 


\section{Abstract}

Purpose: To evaluate the effectiveness of high intensity focused ultrasound (HIFU) combined with suction curettage in the treatment of exogenous cesarean scar pregnancy (CSP).

Methods: A total of 41 patients diagnosed with exogenous CSP were enrolled in this study. All patients received HIFU treatment combined with suction curettage.

Results: Twenty-nine patients were administered one session of HIFU ablation. In addition, the other 12 patients received 2 HIFU sessions. Suction curettage was performed in all patients after HIFU, and no patient was converted to laparoscopy or hysterectomy. The mean blood loss during suction curettage was $99 \mathrm{ml}$. Three patients received two sessions of suction curettage. The success rate of our study was 92.68\%. The mean time for serum $\beta$-HCG normalization was $23.18 \pm 3.13$ days. The average menstruation recovery time was $29.38 \pm 3.34$ days. Based on the blood loss during suction curettage, 41 patients were divided into a bleeding group and a control group. The size of the gestational sac in the bleeding group $(3.80 \pm 0.87 \mathrm{~cm})$ was larger than that in the control group $(3.39 \pm 0.77 \mathrm{~cm})(P<0.05)$. The thickness of the myometrium between the bladder and gestational sac in the bleeding group $(2.37 \pm 0.89 \mathrm{~mm})$ was less than that in the control group $(2.75 \pm 0.75 \mathrm{~mm})(P<0.05)$.

Conclusion: The results suggested that HIFU combined with suction curettage could be considered an effective treatment for exogenous CSP of $<9$ weeks. The size of the gestational sac and the thickness of the myometrium between the bladder and gestational sac might be high-risk factors for blood loss during this treatment.

\section{Introduction}

Cesarean scar pregnancy (CSP) is a rare variant of ectopic pregnancy in which the gestational sac implants into the site of a previous cesarean scar [1]. With the increase in the cesarean section rate and the improvement of diagnostic technology [2], the incidence of CSP is expected to increase further. The overall principle of CSP treatment is to remove gestational tissue, reduce blood loss and ensure the safety of patients. Various treatments for CSP have been studied before, including methotrexate (MTX), uterine artery embolization (UAE), high intensity focused ultrasound (HIFU) and surgery [3-5]. Although an increasing number of CSP cases have been reported, there is still no consensus on its treatment until now [6].

According to the growth direction and location of gestational sac in uterine scars, CSP is divided into two types: endogenous CSP refers to growth of the gestational sac toward the isthmus and uterine cavity, while the gestational sac of exogenous CSP implants into the deep muscle layer of the cesarean scar and grows toward the bladder and abdominal cavity $[7,8]$. Some reports have concluded that there is a higher risk of massive hemorrhage and even death in exogenous CSP because the muscle fibers in previous cesarean scars are relatively insufficient for elastic contractility $[9,10]$. Therefore, effective and safe treatment is particularly important for this kind of patient. As reported before, laparoscopy administered 
for exogenous CSP has achieved good results $[11,12]$. While eliminating pregnancy tissue, laparoscopy could provide an opportunity to repair uterine scar defects, which would be helpful to avoid the recurrence of CSP [13]. However, the exact pathogenetic mechanism of CSP remains unclear. It has been reported that $6 \%-10 \%$ of women after cesarean section have different degrees of scar diverticulum [14], which is significantly higher than the incidence of CSP [15]. CSP patients can have a normal pregnancy again after conservative treatment [16]. These studies suggest that scar diverticulum may not be the only cause of CSP. Although surgery has the advantage of repairing scars at the same time, it might also be complicated by anesthetic complications, postoperative adhesion, and poor healing of local scars [17]. A previous study also concluded that no sufficient evidence was found to elucidate whether reproductive outcomes after CSP are impacted by the management types adopted [18]. In view of the present situation, it seems that effective and less traumatic approaches should be taken. UAE combined with MTX has been reported as an effective treatment for exogenous CSP [19]. However, complications from UAE, such as long-term premature ovarian failure, post thrombotic syndrome, pulmonary embolism, and septic rectal perforation, occur [20-23]. Recently, HIFU has been reported to achieve satisfactory results in the treatment of fibroids and adenomyosis [24, 25]. Several studies have shown that HIFU followed by suction curettage is safe and effective in the treatment of $\operatorname{CSP}[16,26]$. However, the therapeutic effect of HIFU on different types of CSP has not been reported. In this study, we retrospectively evaluated the treatment of HIFU combined with suction curettage to explore whether it is effective and safe for exogenous CSP patients.

\section{Materials And Methods Patient collection}

In this retrospective study we enrolled 41 patients diagnosed with exogenous CSP from September 2016 to September 2020 at the Second Affiliated Hospital, School of Medicine, Zhejiang University. The research protocol was approved by the ethics committee and institutional review board of our institution. The inclusion criteria were as follows: 1) previous history of a prior cesarean scar, 2) history of amenorrhea $<9$ weeks and an increased level of $\beta$-human chorionic gonadotropin ( $\beta$-HCG) (more than 5 $\mathrm{mlU} / \mathrm{mL}$ ), 3) ultrasound (Fig. 1) and magnetic resonance imaging (Fig. 2) meeting the criteria of exogenous CSP recommended by Godin et al [27] and Vial et al [7], with gestational sac implantation into the myometrium of a scar diverticulum and growth toward the bladder and abdominal cavity. Two experienced gynecological radiologists confirmed the sonographic and MRI results of all patients. Patients with heavy bleeding or unstable vital signs were excluded. The clinical characteristics, parameters during treatment, adverse events, and follow-up results were collected.

\section{HIFU ablation}

HIFU was performed by using a PRO200 focused ultrasound therapeutic system (Shenzhen PRO Medical Technology Co. Ltd, Shenzhen, China). The B-mode ultrasound used for monitoring was Mylab70 (Esaote, Genoa, Italy). HIFU ablation was performed on every patient without conscious sedation. The patient was 
placed in the prone position on the HIFU system. The degassed water bag was positioned on the abdominal wall. During the operation, we used ultrasound to choose the location of the target area in real time, and the sagittal plane of ultrasound scanning was selected (Fig. 3). The pregnant tissue was divided into different treatment levels (the spacing was $3 \mathrm{~mm}$ ), and the treatment plan was formulated. HIFU ablation was performed from the innermost part and extended to the outside by section. The sound output power was 250-300 W. HIFU ablation was stopped when color Doppler ultrasound revealed that the blood flow signal of the pregnancy tissue disappeared or the gray level of the target tissue changed. Contrast-enhanced ultrasound was performed to examine the blood perfusion of the pregnancy tissue. If a blood supply was found, another session of HIFU ablation was performed the next day.

\section{Suction curettage}

Suction curettage guided by ultrasound was performed under general anesthesia one to three days after HIFU ablation. The lithotomy position was employed for all patients. We measured the depth of the uterus and then dilated the cervix gradually with the uterine dilators. A $7 \mathrm{~mm}$ suction cannula was inserted into the uterine cavity with a vacuum pressure of $40 \mathrm{~Pa}$. The cannula was moved forth and back and rolled gently to remove the pregnancy tissues. If an ultrasound check showed residual tissue, curettage was performed very gently. If active uterine bleeding $>200 \mathrm{ml}$ occurred during or after suction curettage, we inserted a No. 14 Foley catheter balloon into the intrauterine cavity for compression hemostasis and removed it after 24 hours. The weight of medical gauze was used to measure the blood loss during or after suction curettage.

\section{Follow up}

After suction curettage, vital signs and vaginal bleeding of all patients were closely observed for 48 hours, and then they were discharged. A transvaginal ultrasonography examination was performed one week after suction curettage. If remnant tissue was found, the second session of suction curettage was performed immediately. At the same time, the patients underwent serum $\beta$-HCG testing every week until exhibiting normal levels. Serum $\beta$-HCG levels, the duration of vaginal bleeding, ultrasound assessments, menstruation recovery and adverse effects were followed up.

Successful cases were defined as: (1) no additional methotrexate or surgical intervention; and (2) normalization of serum $\beta$-HCG levels and recovery of menstruation.

\section{Statistical analysis}

Statistical analysis was performed by SPSS software (SPSS 22.0, IBM Company, Chicago, IL). Patient characteristics are described as proportions for categorical variables and were analyzed by the chi square test. Continuous variables with a normal distribution are reported as the mean \pm SD and were analyzed by Student's $t$ test. Continuous variables without a normal distribution are reported as medians and interquartile ranges and were analyzed by the Mann-Whitney $\mathrm{U}$ test. Correlation analysis between variables was performed by Spearman rank analysis. A $P$ value $<0.05$ was defined as a significant difference. 


\section{Results}

\section{Characteristics of exogenous CSP patients}

Patient characteristics are summarized in Table 1. The median age of the patients was 29 years. The mean BMI was $22.62 \pm 5.27 \mathrm{~kg} / \mathrm{m}^{2}$. The average gestational age was $50.31 \pm 8.27$ days. The median interval from the last cesarean section to CSP was 38 months. Among all patients, 20 patients (48.78\%) had one previous cesarean delivery, 18 patients (43.90\%) had two such deliveries, and 3 patients $(7.32 \%)$ had three such deliveries. Thirteen patients $(31.71 \%)$ had both light painless vaginal bleeding and lower abdominal pain. Twelve patients $(29.27 \%)$ suffered from abdominal pain without vaginal bleeding. Sixteen patients $(39.02 \%)$ complained of only light painless vaginal bleeding. Fetal cardiac activity was found in 6 patients (14.63\%). Before the treatment the median serum $\beta$-HCG level was $26,207 \pm 8492$ $\mathrm{mlU} / \mathrm{ml}$. The average gestation sac size was $3.49 \pm 0.94 \mathrm{~cm}$. The median thickness of myometrium between the bladder and the gestational sac was $2.65 \pm 1.10 \mathrm{~mm}$.

Table 1

Demographic characteristics of exogenous CSP patients $(n=41)$

\begin{tabular}{|ll|}
\hline Variables & value \\
\hline Maternal age (years) & $29(25,39)$ \\
BMI $\left(\mathrm{kg} / \mathrm{m}^{2}\right)$ & $22.62 \pm 5.27$ \\
Gestational age (days) & $50.31 \pm 8.27$ \\
Time interval since last CS (months) & $38(21,84)$ \\
Number of previous CS ( $)$ & \\
1 & $20(48.78 \%)$ \\
2 & $18(43.90 \%)$ \\
3 & $3(7.32 \%)$ \\
\hline Abnormal pain only (n) & $12(29.27 \%)$ \\
\hline Light painless vaginal bleeding only (n) & $16(39.02 \%)$ \\
\hline Light painless vaginal bleeding and abdominal pain (n) & $13(31.71 \%)$ \\
Fetal cardiatic activity & $6(14.63 \%)$ \\
\hline Pre-treatment serum $\beta$-HCG (mIU/mL) & $26207 \pm 8492$ \\
Gestation sac size (cm) & $3.49 \pm 0.94$ \\
Thickness of myometrium between gestation sac and the bladder & $2.65 \pm 1.10$ \\
\hline (mm) & \\
\hline -HCG = $\beta$-human chorionic gonadotropin; CS = cesarean section & \\
\hline
\end{tabular}




\section{HIFU ablation evaluation}

HIFU treatment was successfully carried out for all patients (Table 2). One session of HIFU ablation therapy was performed for 29 patients $(70.73 \%)$. The other 12 patients $(29.27 \%)$ received 2 HIFU sessions. The average HIFU treatment time was 83 minutes. The median HIFU sonication time was $705 \mathrm{~s}$. After HIFU ablation, no blood perfusion was found in the pregnancy tissue by contrast-enhanced ultrasound (Fig. 4,5). Simultaneously, we could not detect fetal cardiac activity. During HIFU ablation, all patients complained of pain in the sacra or lower abdomen. A 10-point scale was used, and the pain score ranged from 1 to 3 points. The pain was relieved within 1 week without any special medical treatment. A hot skin sensation was complained of by fourteen patients. However, we found no skin burns in those patients. 
Table 2

The treatment results

\begin{tabular}{|c|c|}
\hline Variables & value \\
\hline \multicolumn{2}{|l|}{ HIFU } \\
\hline Median treatment time(min) & $83(60,132)$ \\
\hline Median sonication time(s) & $705(614,1142)$ \\
\hline \multicolumn{2}{|l|}{ Session of HIFU ablation } \\
\hline 1 & $29(70.73 \%)$ \\
\hline 2 & $12(29.27 \%)$ \\
\hline \multicolumn{2}{|l|}{ Suction curettage } \\
\hline The uterus cavity depth(cm) & $9.64 \pm 1.43$ \\
\hline Surgical time(min) & $35.45 \pm 10.23$ \\
\hline Blood loss during curettage (ml) & $99(30,240)$ \\
\hline \multicolumn{2}{|l|}{ Treatments for bleeding during suction curettage } \\
\hline No hemostasis (n) & $29(70.73 \%)$ \\
\hline Foley catheter balloon used (n) & $12(29.27 \%)$ \\
\hline \multicolumn{2}{|l|}{ Session of suction curettage } \\
\hline 1 & $38(92.68 \%)$ \\
\hline 2 & $3(7.32 \%)$ \\
\hline \multicolumn{2}{|l|}{ Follow up } \\
\hline Duration of vaginal bleeding post-curettage (days) & $9.72 \pm 3.92$ \\
\hline Time of menstruation recovery(days) & $29.38 \pm 3.34$ \\
\hline Time for serum $\beta$-HCG normalization(days) & $23.18 \pm 3.13$ \\
\hline
\end{tabular}


Table 3

Comparison of characteristics of exogenous CSP patients in two groups

\begin{tabular}{|llll|}
\hline Variables & The bleeding group $(\mathrm{n}=$ & $\begin{array}{l}\text { The control group }(\mathbf{n}= \\
\text { 29) }\end{array}$ & $\boldsymbol{P}$ \\
\hline Maternal age(years) & $30(24,41)$ & $29(25,38)$ & 0.453 \\
BMI & $23.45 \pm 3.45$ & $22.87 \pm 2.13$ & 0.367 \\
Gestational age & $51.23 \pm 4.25$ & $49.83 \pm 5.15$ & 0.312 \\
Number of previous CS $(\mathrm{n})$ & $2(1-3)$ & $2(1-3)$ & 0.419 \\
Time Interval since last CS $(\mathrm{m})$ & $42(25,89)$ & $37(19,82)$ & 0.187 \\
Pre-treatment serum $\beta$-HCG $(\mathrm{mlU} / \mathrm{mL})$ & $27148 \pm 6746$ & $25864 \pm 8769$ & 0.328 \\
Gestational sac diameter $(\mathrm{mm})$ & $3.80 \pm 0.87$ & $3.39 \pm 0.77$ & 0.019 \\
Thickness of myometrium $(\mathrm{mm})$ & $2.37 \pm 0.89$ & $2.75 \pm 0.75$ & 0.014 \\
\hline $\begin{array}{l}\text { B-HCG }=\beta \text {-human chorionic } \\
\text { gonadotropin; }\end{array}$ & $\mathrm{CS}=$ cesarean section & & \\
\hline
\end{tabular}

\section{Suction curettage assessment and follow-up}

Suction curettage was performed on all patients after HIFU treatment (Table 2). No patient was converted to laparoscopy or hysterectomy. The median blood loss during suction curettage was $99 \mathrm{ml}$. We inserted the No. 14 Foley catheter balloon into the intrauterine cavity to manage massive vaginal bleeding (>200 $\mathrm{ml}$ ) in 12 patients. The catheter balloon was removed 24 hours later. Ultrasound checks were performed by an ultrasound specialist for every patient one week after suction curettage. The pregnancy tissues were successfully removed in 38 patients $(92.68 \%)$. Three patients $(7.32 \%)$ received a second session of suction curettage with blood loss of $20 \mathrm{ml}$ for remnant pregnancy tissues.

All patients received follow-up through clinical visits. The median period of vaginal bleeding was $9.72 \pm$ 3.92 days. The mean time for $\beta$-HCG normalization was $23.18 \pm 3.13$ days. The average time of menstruation recovery was $29.38 \pm 3.34$ days (Table 2 ). No complications occurred during the follow-up period.

\section{Analysis of risk factors for blood loss during suction curettage}

Based on the use of catheter balloons during suction curettage, 41 patients were divided into two groups. The patients who used catheter balloons were considered the bleeding group (blood loss $>200 \mathrm{ml}$ ). The other patients were grouped into the control group. Between the two groups, we found no significant difference in terms of age, BMI, gestational age, number of previous cesarean sections, time interval from the last cesarean section, or $\beta$-HCG level before treatment $(P>0.05)$. However, the size of gestational sac 
in the bleeding group $(3.80 \pm 0.87 \mathrm{~cm})$ was larger than that in the control group $(3.39 \pm 0.77 \mathrm{~cm})(P<$ 0.05). The thickness of the interval myometrium between the bladder and gestational sac in the bleeding group $(2.37 \pm 0.89 \mathrm{~mm})$ was less than that in the control group $(2.75 \pm 0.75 \mathrm{~mm})(P<0.01)$. In all exogenous CSP patients, there was a positive correlation between the size of the gestational sac and blood loss during suction curettage $(r=0.401, P<0.01)$. Meanwhile, the thickness of the interval myometrium between the bladder and gestational sac had a negative correlation with blood loss during suction curettage $(r=-0.423, P<0.01)$.

\section{Discussion}

To our knowledge, this is the first report on the use of HIFU combined with suction curettage for treating exogenous CSP. The success rate in this study was $92.68 \%$ and no patient was converted to laparoscopy or hysterectomy. The median intraoperative blood loss during suction curettage was $99 \mathrm{ml}$. The average time for serum $\beta$-HCG level normalization was $23.18 \pm 3.13$ days, and the median time for menstruation recovery was $29.38 \pm 3.34$ days. Although there are some deficiencies in HCG levels and menstrual recovery compared with those after laparoscopy $[11,12]$, our protocol provides the possibility of one conservative treatment for exogenous CSP patients. We also reviewed the literature about the treatment of UAE combined with suction curettage for CSP. Introspective blood loss ranged from $14 \mathrm{ml}$ to $114 \mathrm{ml}$, and serum $\beta$-HCG returned to normal levels within 15 to 29 days $[26,28,29]$. Our study obtained the similar results as those from the treatment of UAE combined with suction curettage and avoided the complications of UAE.

Theoretically, HIFU mainly uses high intensity ultrasound to focus on the internal target of the body in vitro. We speculate that HIFU contributes to the treatment of exogenous CSP in three ways. First, HIFU ablation can cause necrosis of the corresponding lesion cells. Through the mechanical effect of high intensity ultrasound, the high-temperature thermal effect formed an instantaneous high temperature > $60^{\circ} \mathrm{C}$, which led to necrosis in the pregnancy tissue. Second, the cavitation effect of HIFU could loosen the adhesion between the myometrium at the uterine scar and the gestational sac, which would be helpful for removing the pregnancy tissue [30]. Finally, HIFU has been reported to be used for the ablation of small vessels with a diameter $<2 \mathrm{~mm}$ [31]. The thermal energy deposited in the pregnancy tissue can destroy small blood vessels. As seen on color Doppler assessment, the blood perfusion in the pregnancy tissue disappeared. For the reasons mentioned above, HIFU could make suction curettage a smoother process for removing the pregnancy tissue and reduce the risk of heavy hemorrhage. As reported before, adverse effects, such as sciatic and lower abdominal pain, injury to the bowel and bladder, fever, and skin burns, occur during HIFU ablation [32-34]. In the ablation for exogenous CSP, the target site was located at the anterior wall of the cervix, which was located away from the bowl in the pelvic cavity. Ablation began from the innermost part, which was not near the bladder. With simultaneous ultrasound monitoring, HIFU ablation in our study caused no damage to surrounding organs. Although all patients complained of abdominal or sacral pain during the HIFU ablation, no patients needed further treatment. 
Due to the characteristics of exogenous CSP, there is a risk of uterine perforation and substantial hemorrhage during suction curettage. To avoid uterine perforation during suction curettage, we first carried out vacuum suction. If an ultrasound check showed residual tissue, curettage was performed very gently. In our study, no uterine perforations occurred. A previous study reported that perforation of the uterus occurred in a CSP patient during suction curettage after HIFU ablation [35]. The author attributed this event to the $2 \mathrm{~mm}$ thickness of the interval myometrium between the bladder and gestation sac. In our study, the thickness of the thinnest interval myometrium was $1.5 \mathrm{~mm}$, but no uterine perforation occurred. Therefore, we deduce that uterine perforation is a result of comprehensive factors. For patients with bleeding greater than $200 \mathrm{ml}$, we used a Foley balloon catheter to compress the hemorrhage, which avoided the possibility of conversion to laparotomy. However, there were still 3 patients who had to undergo a second suction curettage. We found that all three of these patients were administered Foley balloon catheters during the suction curettage. Thus, the suction curettage was interrupted, which resulted in residual pregnancy tissue.

We also found that the size of the gestational sac and the thickness of the interval myometrium between the bladder and gestational sac were correlated with blood loss during suction curettage. Our results were consistent with those of previous studies [36,37]. Adhesion between the myometrium at the uterine scar and the gestational sac will form bleeding wounds as the pregnancy tissue is removed [38]. The wound will expand with the increase in the gestational sac, which also elevates the risk of hemorrhage. The weakness of the myometrium is accompanied by poor contractility, which makes it difficult to close the bleeding vessels $[39,40]$. We also found no significant difference in terms of age, $\mathrm{BMI}$, gestational age, interval time from last CS, or $\beta$-HCG level before treatment between the two groups. We noticed that a previous study considered the $\beta$-HCG level to be a risk factor for massive hemorrhage [41]. As a biochemical index representing trophoblastic cell activity, the $\beta-H C G$ level of exogenous CSP may not be high due to the muscular layer defects and insufficiency of the blood supply. The inconsistency might result from the different grouping standards adopted in different studies.

In conclusion, our results indicate that HIFU combined with suction curettage is effective and safe in the treatment of exogenous CSP of $<9$ weeks. We also found that the size of the gestational sac and the thickness of the interval myometrium between the bladder and gestational sac might be high-risk factors for blood loss during this treatment. Limited by the retrospective analysis and the sample number, we should validate our findings by carrying out prospective and large-scale multicenter studies in the future.

\section{Declarations}

\section{Competing interests:}

The authors declare that they have no conflicts of interest and nothing to disclose.

\section{Funding:}


This study was sponsored by Zhejiang Provincial Public Welfare Technology Application Research Project in China. (LGF18H040006)

\section{Ethics approval:}

Institutional Review Board approval waiving informed consent was obtained for this retrospective study (2021-0458).

\section{Authors' contributions:}

Lin Mu: Project development, data collection and manuscript writing. HF Weng: Data collection and management. XY Wang: Data analysis.

\section{References}

1. Timor-Tritsch IE, Monteagudo A, Santos R, et al. (2012) The diagnosis, treatment, and follow-up of cesarean scar pregnancy. Am J Obstet Gynecol 207:44.e1-13. https://doi.org/10.1016/j.ajog.2012.04.018

2. Liu D, Yang M, Wu Q. (2018) Application of ultrasonography in the diagnosis and treatment of cesarean scar pregnancy. Clin Chim Acta. 486:291-297.https://doi.org/10.1016/j.cca.2018.08.012.

3. Xiao Z, Cheng D, Chen J, Yang J, Xu W, Xie Q. (2019) The effects of methotrexate and uterine arterial embolization in patients with cesarean scar pregnancy: A retrospective case-control study. Medicine 98(11):e14913. https://doi.org/10.1097/MD.0000000000014913.

4. XG Zhu, XL Deng, SS Xiao, YJ Wan, M Xue. (2016) A comparison of high intensity focused ultrasound and uterine artery embolisation for the management of caesarean scar pregnancy. International Journal of Hyperthermia 32(2):144-150. https://doi.org/10.3109/02656736.2015.1104733.

5. DB Wang, YH Chen, ZF Zhang, P Chen, KR Lin. (2014) Evaluation of the transvaginal resection of low segment cesarean scar ectopic pregnancies. Fertil Steril 101:602-606. https://doi.org/10.1016/j.fertnstert.2013.10.024.

6. Kathrine BP, Elise H, Christian RL, and Henriette SN. (2016) Cesarean scar pregnancy: a systematic review of treatment studies. Fertil Steril 105:958-967. https://doi.org/10.1016/j.fertnstert.2015.12.130.

7. Vial Y, Petignat P, Hohlfeld P. (2000) Pregnancy in a Cesarean scar. Ultrasound Obst Gyn 16:592-593. https://doi.org/10.1046/j.1469-0705.2000.00300-2.x.

8. Osborn DA, Williams TR, Craig BM. (2012) Cesarean scar pregnancy: sonographic and magnetic resonance imaging findings, complications, and treatment. J Ultrasound Med 31:1449-1456. https://doi.org/10.7863/jum.2012.31.9.1449.

9. Du YJ, Zhang XH, Wang LQ. (2015) Risk factors for haemorrhage during suction curettage after uterine artery embolization for treating caesarean scar pregnancy: a case-control study. Gynecol 
Obstet Investig. 80:259-64. https://doi.org/10.1159/000381263.

10. Maheux-Lacroix S, Li F, Bujold E, Nesbitt-Hawes E, Deans R, Abbott J. (2017) Cesarean scar pregnancies: A systematic review of treatment options. J Minim Invasive Gynecol 24:915-925. https://doi.org/10.1016/j.jmig.2017.05.019.

11. Zhang C, Liu G, Guo Q, Li Y, Yang Q. (2016) Foley Catheter-Assisted Laparoscopic Treatment of Type II Cesarean Scar Pregnancy. J Minim Invasive Gynecol 23:639-42.https://doi.org/10.1016/j.jmig.

12. Qi F, Chai ZY, Liu MM, Zheng LZ, Zhu Y, Chen ZW, Lv WG. (2019) Type 2 Cesarean Scar Pregnancy Successfully Treated via Hysteroscopy-Assisted Laparoscopy. J Minim Invasive Gynecol. 26(7):12731281. https://doi.org/10.1016/j.jmig.2018.11.019.

13. Guangwei Wang, Xiaofei Liu, Fangfang Bi, Lili Yin, Dandan Wang and Qing Yang. (2014) Evaluation of the efficacy of laparoscopic resection for the management of exogenous cesarean scar pregnancy. Fertil and steril 11(5):1501-1507. https://doi.org/10.1016/j.fertnstert.2014.01.045.

14. Marotta ML, Donnez J, Squifflet J, Jadoul P, Darii N, Donnez O. (2013) Laparoscopic repair of postcesarean section uterine scar defects diagnosed in nonpregnant women. J Minim Invasive Gynecol 20:386-391. https://doi.org/10.1016/j.jmig.2012.12.006.

15. Zhai JF, Xu M, Zhang B, et al. Treatments of caesarean scar pregnancy and the corresponding results in ten years. Eur Rev Med Pharmacol Sci. 2015;19:2523-2527. https://doi.org/

16. Cai Zhang, Yuqi Zhang, Jia He, Lian Zhang. (2019) Outcomes of subsequent pregnancies in patients following treatment of cesarean scar pregnancy with high intensity focused ultrasound followed by ultrasound-guided dilation and curettage. International Journal of Hyperthermia, 36(1):925-930. https://doi.org/10.1080/02656736.2019.1654619.

17. Awonuga AO, Fletcher NM, Saed GM, Diamond MP. (2011) Postoperative adhesion development following cesarean and open intra-abdominal gynecological operations: a review. Reprod Sci. 2011;18:1166-1185. https://doi.org/10.1177/1933719111414206.

18. Morlando M, Buca D, Timor-Tritsch I, Cali G, Palacios-Jaraquemada J, et al. (2020) Reproductive outcome after cesarean scar pregnancy: A systematic review and meta-analysis. Acta Obstet Gynecol Scand.99(10):1278-1289. https://doi.org/10.1111/aogs.13918.

19. Sun YY, Xi XW, Yan Q, Qiao QQ, Feng YJ, Zhu YP. (2015) Management of type II unruptured cesarean scar pregnancy: Comparison of gestational mass excision and uterine artery embolization combined with methotrexate. Taiwan J Obstet Gynecol. 54(5):489-92.

https://doi.org/10.1016/j.tjog.2015.08.002.

20. Qiu J, Fu Y, Huang X, et al. (2018) Acute pulmonary embolism in a patient with cesarean scar pregnancy after receiving uterine artery embolization: a case report. Ther Clin Risk Manag 14:117120. https://doi.org/2147/TCRM.S147754

21. Wang $Y$, Huang X. (2018) Sepsis after uterine artery embolization-assisted termination of pregnancy with complete placenta previa: A case report. J Int Med Res 46:546-50. https://doi.org/10.1177/0300060517723257. 
22. Mallick R,Okojie A, Ajala T. (2016) Rectal perforation: Anunusual complication of uterine artery embolisation. J Obstet Gynaecol 36:867-868. https://doi.org/10.1080/01443615.2016.1180506.

23. Kaump GR, Spies JB. (2013) The impact of uterine artery embolization on ovarian function. J Vasc Interv Radiol 24:459-467. https://doi.org/10.1016/j.jvir.2012.12.002.

24. Savic LJ, Lin MD, Duran $R_{\Perp}$, et al. (2015) Three-dimensional quantitative assessment of lesion response to MR-guided high-intensity focused ultrasound treatment of uterine fibroids. Acad Radiol. 22(9):1199-1205. https://doi.org/10.1016/j.acra.2015.05.008.

25. Liu X, Wang W, Wang Y, Wang Y, Li Q, Tang J. (2016) Clinical predictors of long-term success in ultrasound-guided high-intensity focused ultrasound ablation treatment for adenomyosis: a retrospective study. Medicine. 95(3):e2443. https://doi.org/10.1097/MD.0000000000002443.

26. Hong Y, Guo Q, Pu Y, Lu D, Hu M. (2017) Outcome of high-intensity focused ultrasound and uterine artery embolization in the treatment and management of cesarean scar pregnancy: A retrospective study. Medicine (Baltimore). 96(30):e7687. https://doi.org/10.1097/MD.0000000000007687.

27. Godin PA, Bassil S, Donnez J. (1997) An ectopic pregnancy developing in a previous caesarean section scar. Fertil Steril. 67:398-400. https://doi.org/10.1016/S0015-0282(97)81930-9.

28. Zhang C, Zhang Y, He J, Zhang L. (2019) Outcomes of subsequent pregnancies in patients following treatment of cesarean scar pregnancy with high intensity focused ultrasound followed by ultrasound-guided dilation and curettage. Int J Hyperthermia. 36(1):926-931. https://doi.org/10.1080/02656736.2019.1654619.

29. Chen L, Xiao S, Zhu X, He S, Xue M. (2019) Analysis of the Reproductive Outcome of Patients with Cesarean Scar Pregnancy Treated by High-Intensity Focused Ultrasound and Uterine Artery Embolization: A Retrospective Cohort Study. J Minim Invasive Gynecol. 26(5):883-890. https://doi.org/10.1016/j.jmig.2018.09.001.

30. Copelan A, Hartman J, Chehab M, Venkatesan AM. (2015) High-Intensity focused ultrasound: current status for image-guided therapy. Semin Intervent Radiol. 32:398-415. https://doi.org/10.1055/s0035-1564793.

31. Wu F, Chen WZ, Bai J, et al. (2002) Tumor vessel destruction resulting from high-intensity focused ultrasound in patients with solid malignancies. Ultrasound Med Biol. 28:535-542. https://doi.org/10.1016/s0301-5629(01)00515-4.

32. Haar GT, Coussios C. (2007) High intensity focused ultrasound: physical principles and devices. Int J Hyperthermia 23:89-104. https://doi.org/10.1080/02656730601186138.

33. Shaw CJ, ter Haar GR, Rivens IH, et al. (2014) Pathophysiological mechanisms of high-intensity focused ultrasound-mediated vascular occlusion and relevance to non-invasive fetal surgery. J R Soc Interface 11:20140029. https://doi.org/10.1098/rsif.2014.0029.

34. Stewart EA, Rabinovici J, Tempany CM, et al. (2006) Clinical outcomes of focused ultrasound surgery for the treatment of uterine fibroids. Fertil Steril 85:22-29. https://doi.org/10.1016/j.fertnstert.2005.04.072. 
35. Zhu X, Deng X, Wan Y, Xiao S, Huang J, et al. (2015) High-intensity focused ultrasound combined with suction curettage for the treatment of cesarean scar pregnancy Medicine94(18):e854. https://doi.org/10.1097/MD.0000000000000854.

36. Zhang Y, Zhang Z, Liu X, Zhang L, Hong F, Lu M.Zhang Y, et al. (2021) Risk factors for massive hemorrhage during the treatment of cesarean scar pregnancy: a systematic review and metaanalysis Arch Gynecol Obstet. 303(2):321-328. https://doi.org/10.1007/s00404-020-05877-9.

37. Zhang Y, Zhang C, He J, Bai J, Zhang L.Zhang Y, et al. (2018) The impact of gestational sac size on the effectiveness and safety of high intensity focused ultrasound combined with ultrasound-guided suction curettage treatment for caesarean scar pregnancy Int J Hyperthermia. 35(1):291-297. https://doi.org/10.1080/02656736.2018.1496485.

38. Le A, Li M, Xu YH et al. (2019) Different surgical approaches to 313 cesarean scar pregnancies. J Minim Invasive Gynecol 26: 148-152. https://doi.org/10.1016/j.jmig.2018.03.035.

39. Shao MJ, Hu MX, Xu XJ et al (2013) Management of caesarean scar pregnancies using an intrauterine or abdominal approach based on the myometrial thickness between the gestational mass and the bladder wall. Gynecol Obs Invest 76:151-157. https://doi.org/10.1016/j.ejogrb.2019.04.008.

40. Ma Y, Shao M, Shao X, et al, (2017) Analysis of risk factors for ntraoperative hemorrhage of cesarean scar pregnancy. Medicine 96(25):e7327区https://doi.org/10.1097/MD.0000000000007327.

41. Fang Q, Sun L, Tang $Y$ et al (2017) Quantitative risk assessment to guide the treatment of cesarean scar pregnancy. Int J Gynaecol Obs 139:78-83. https://doi.org/10.1002/ijgo.12240.

\section{Figures}




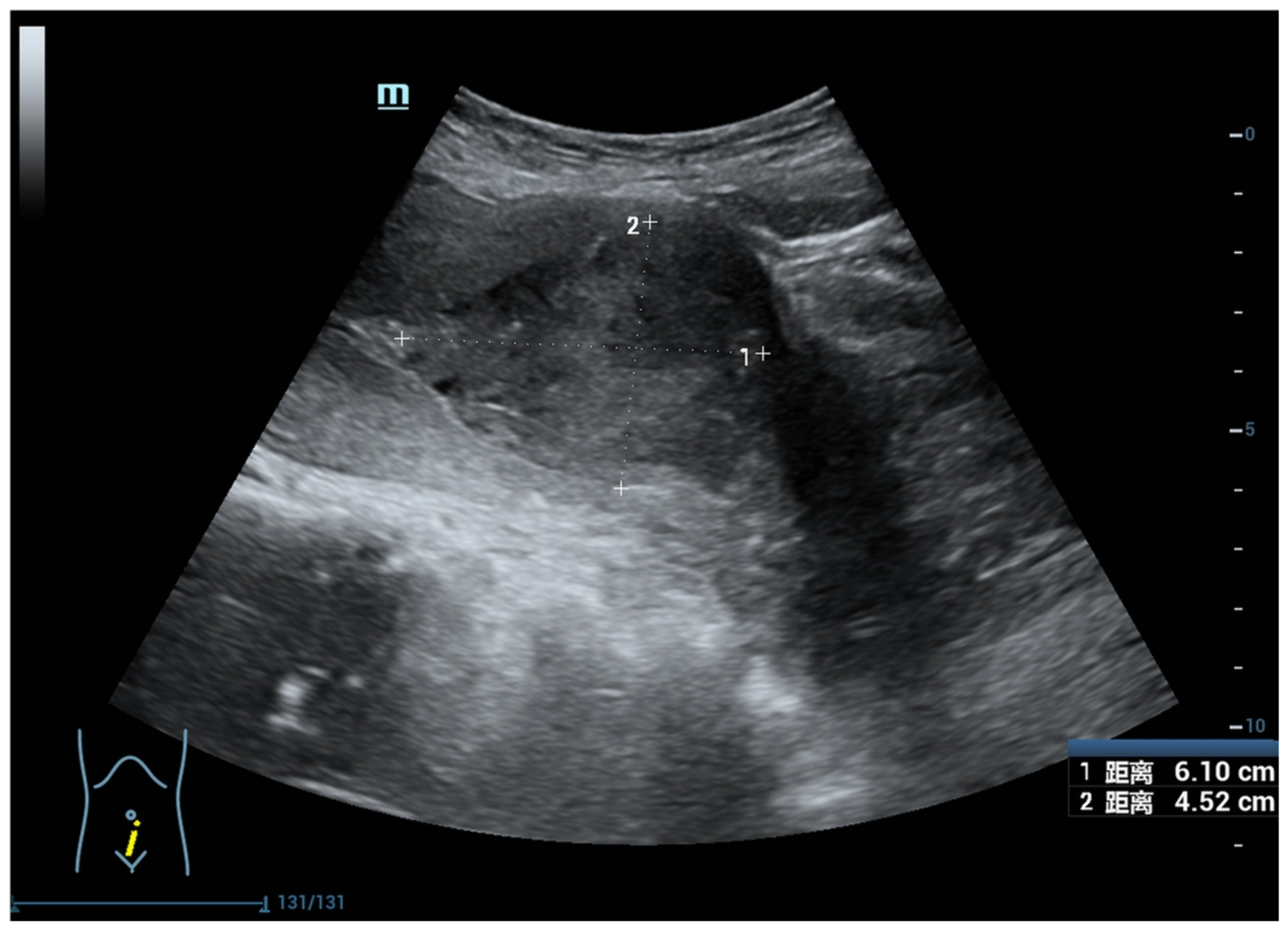

Figure 1

Exogenous cesarean scar pregnancy located in the previous cesarean scar. 


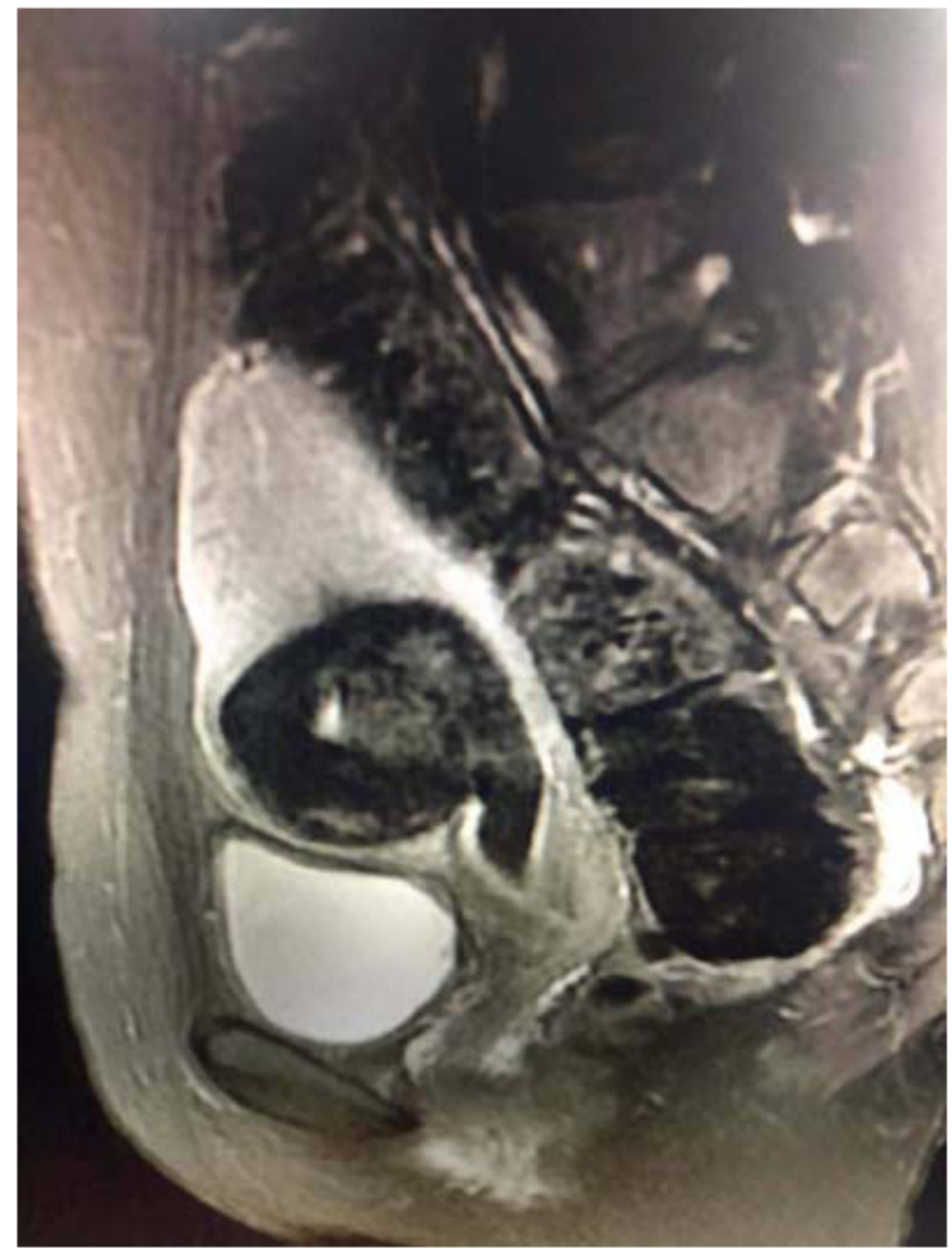

Figure 2

Sagittal view of the magnetic resonance imaging showed a gestational sac located in the previous cesarean scar. 


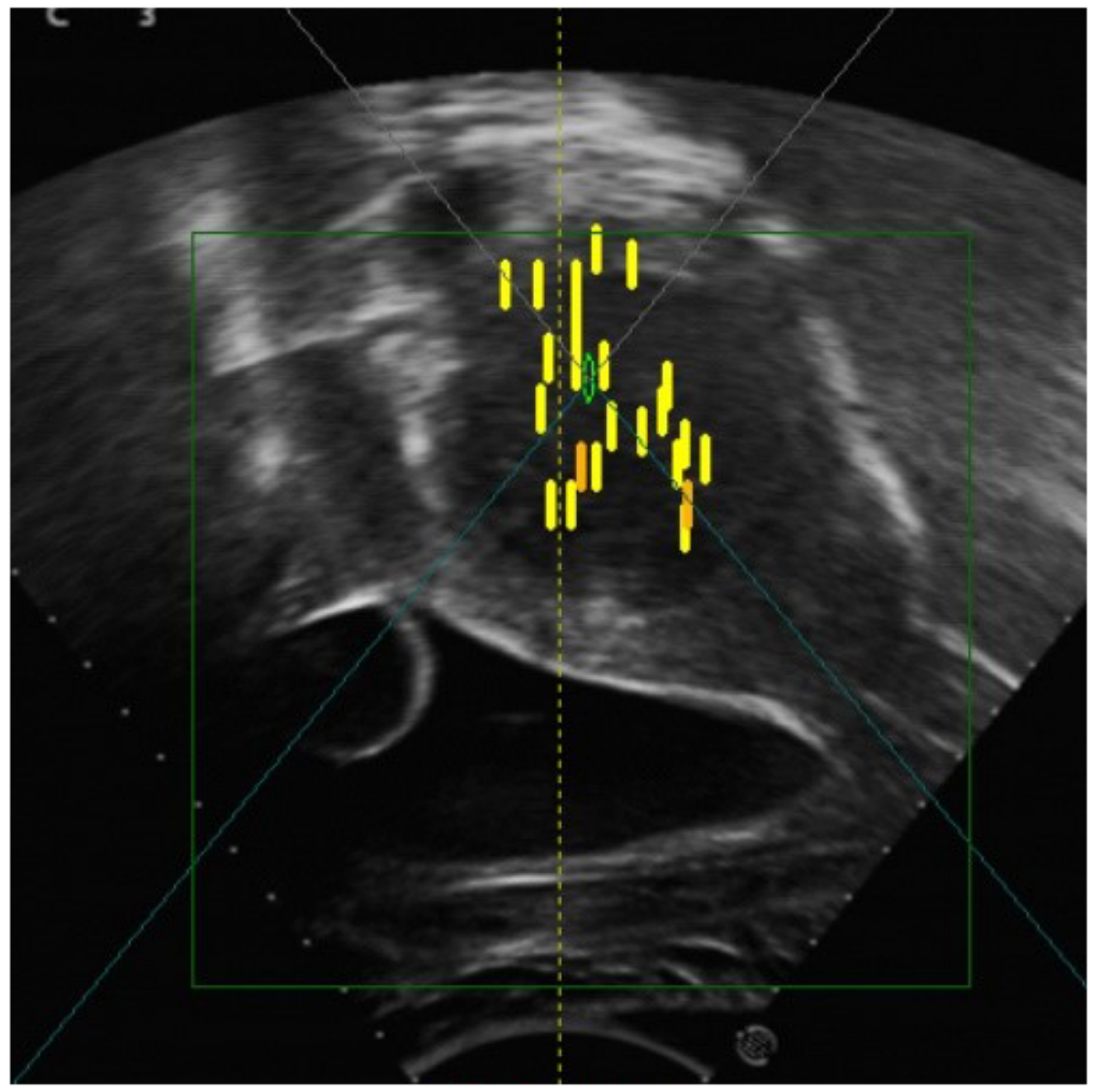

\section{Figure 3}

Treatment mode of high intensity focused ultrasound ablation.

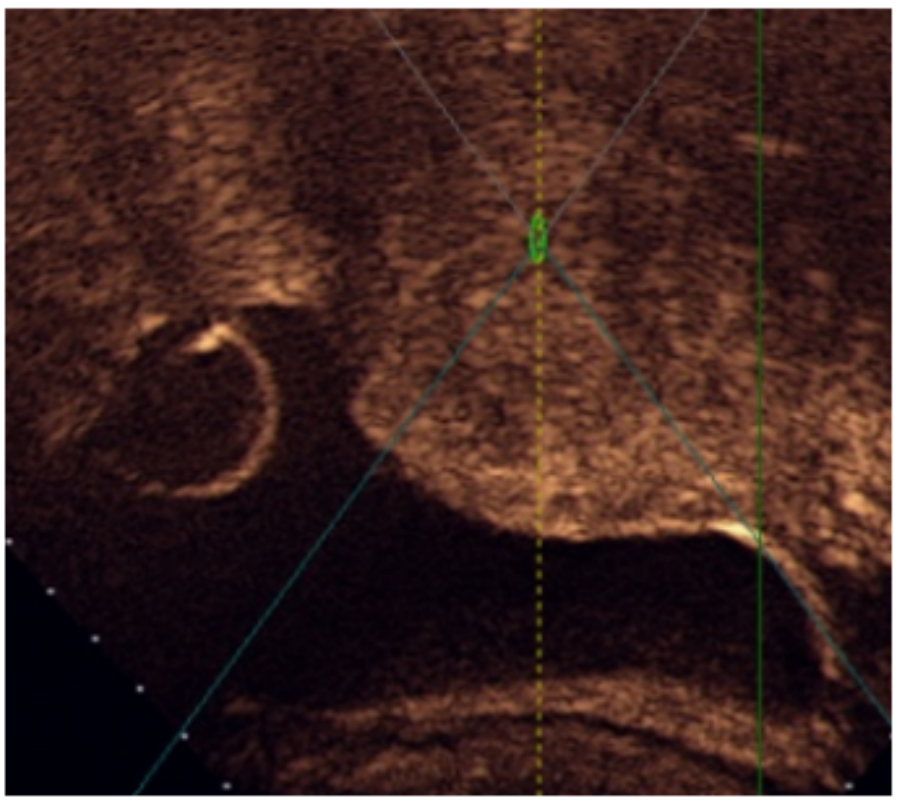

Figure 4 
Abundant perfusion in the myometrium of the surrounding CSP scar was found by contrast enhanced ultrasound before HIFU.

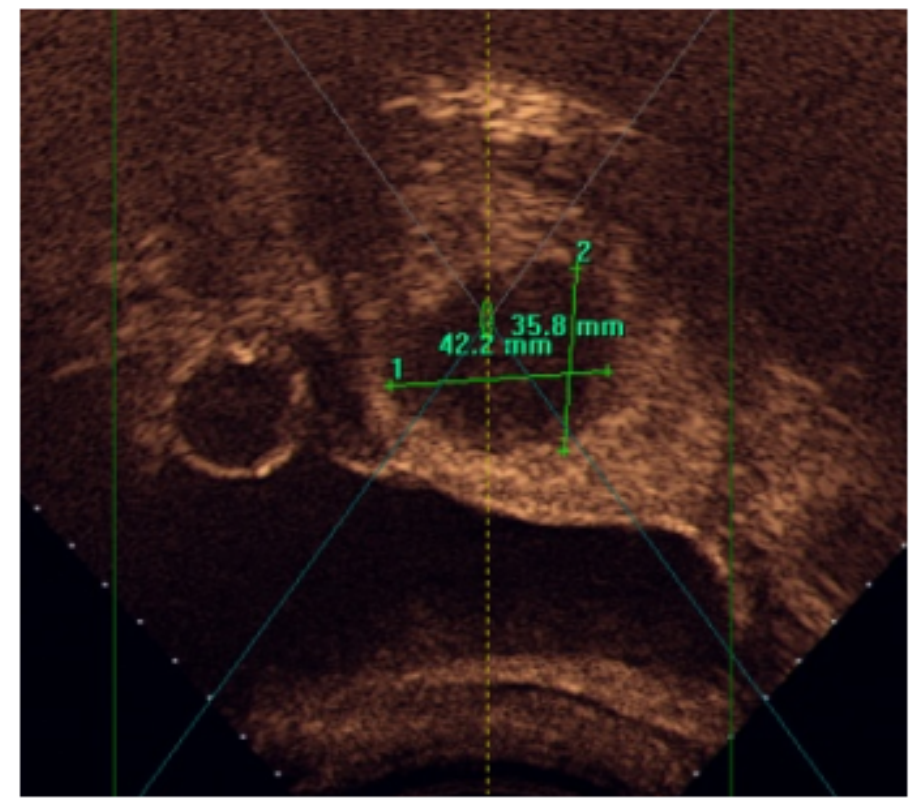

\section{Figure 5}

Contrast enhanced ultrasound revealed no enhancement in the myometrium of the CSP scar after HIFU. 